\title{
A Model for Implementing Temperature Information Systems in South-east Nigeria
}

\author{
Anthony T. Umerah ${ }^{a}$, Eric C. Okafor ${ }^{b}$ \\ ${ }^{a}$ Department of Computer Science, Ebonyi State University Abakaliki, Ebonyi State, Nigeria \\ ${ }^{b}$ Department of Computer Engineering, Enugu State University of Science and Technology, Enugu State, \\ Nigeria
}

Received: 26 March 2018; Accepted: 08 June 2018; Published: 08 September 2018

\begin{abstract}
The aim of this study is to find an efficient and robust model for building temperature information systems in South-East Nigeria. The study obtained daily mean temperature data records for a period of 10years of the capture cities of Enugu, Abakaliki and Owerri, and applied the data to several forecasting models: 3 \& 4 point moving averages (MA), the Single Exponential Smoothing (SES) and the time dependent regression model for intercept and non-intercept models as well as linear and non-linear models. The comparison of various forecasting models was made based on the following performance evaluation methods: F-values, Mean Square Error (MSE) and Root Mean Square Error (RMSE) where applicable. The findings show that the power model with statistical characteristics of F-values = 1513.71(Enugu), 1523.622(Abakaliki) and 1514.103(Owerri), MSE $=0.655$ (Enugu), 0.6495(Abakaliki), and 0.5925(Owerri), and RMSE = 0.80524(Enugu), 0.80292(Abakaliki) and 0.76703 (Owerri), is the best model for temperature information systems because of its consistency in minimizing errors, and largeness of F-values. This is followed by the single exponential smoothing technique and logarithmic model. This study therefore presents and recommends the power regression model as the most robust model for temperature forecasting in South-East Nigeria.
\end{abstract}

Index Terms: Temperature information systems, Forecasting models, F-value, Mean Square Error, Root Mean Square Error, Temperature forecasting.

(C) 2018 Published by MECS Publisher. Selection and/or peer review under responsibility of the Research Association of Modern Education and Computer Science.

\footnotetext{
* Corresponding author.
}

E-mail address: 


\section{Introduction}

South-east Nigeria is situated between latitudes $7^{\circ} 07^{\prime} \mathrm{N}$ and $3^{\circ} 90^{\prime} \mathrm{N}$ and longitudes $6^{\circ} 51^{\prime} \mathrm{E}$ and $8^{\circ} 30^{\prime} \mathrm{E}$. The region comprises of Abia, Anambra, Ebonyi, Enugu, and Imo States and enclosed a total land area of 17,545 $\mathrm{km}^{2}$ [1]. The region has high solar radiation with uniformly high temperatures although the year [2]. Mean yearly temperatures range from $25^{\circ} \mathrm{C}$ to $27{ }^{\circ} \mathrm{C}$. Mean yearly radiation is low in coastal areas of the region due to constant cloud cover.

Serious environmental problems are likely to arise in Nigeria, this is in relationship with the possible global warming which results from releases of greenhouse gases into the atmosphere.

According to [3], climate change is a substantial and lasting change in the distribution of weather patterns over a long period of time, they noted that it may be a change in average weather conditions, or in the distribution of weather around the average conditions. Change in climatic conditions of any geographic region may be caused by factors such as changes in the levels of solar radiation that reaches the earth surface, biotic processes, volcanic eruptions and plate tectonics [3]. Similarly [4] defined Climate change as a change in collective patterns of expression in various elements of weather, noting that climate change is a permanent departure of climatic patterns from mean values of observed climate indices.

In their study of risk management and challenges of climate change in Nigeria, [5] reviewed the incidences and consequences of climatic change and the vulnerability of Nigeria to climate change. Their findings show that deforestation, industrial releases, improper disposal of sewage are human activities responsible for climate change. The study also found out that drought, erosion and flooding constitute the challenges resulting from climate change, and consequently that government agencies in charge of environmental issues do not really help to reduce the risk of climate change in Nigeria.

Climate change is a global problem that requires stringent approach and it is also one of the most important issues of discuss in the global political agenda. The existence of hazards such as desertification, droughts, storm, global warming, floods, acid rain, hurricanes, and erosion are very rampant and have become serious issues of global discuss in recent years. These hazards are giving the present generation much concern owing to their renewed intensities. The major weather element of utmost concern to Nigerians are the rainfall and temperature patterns, as they are the major determinants of economic activities such as farming, irrigation, transportation, and so on in Nigeria.

One of the major problems hindering to some extent, the control of climate change is in finding an efficient prediction model for weather elements. Several models of temperature predictions abound, but the efficacies are quite doubtful as they demand costly equipment and rigorous methods to achieve the desired goals. This present study employs easy to use statistical models with the best interest of finding the most robust (with less assumptions and simple to use) model for building temperature information systems.

\section{Aim and Objectives of the Study}

The aim of this study is to find an efficient and robust model for building temperature information systems. The specific objectives are:

1) To obtain daily mean temperature data records for a period of $10 y e a r s$ in the study area.

2) To fit the various forecasting models using the data obtained.

3) To compare forecasting models and determine the most robust model for temperature prediction in south-east Nigeria.

4) To determine a simple Excel formula to implement the best model as a program module for temperature prediction in information systems. 


\section{Related Works}

Several studies have been conducted on weather prediction especially on temperature and solar radiation forecasting.

In their investigation on the accuracy of a soft computing procedure for forecasting solar radiation based on a series of measured meteorological data: minimum and maximum temperatures, monthly mean temperature and sunshine duration obtained from a meteorological station located in Iseyin Nigeria [6], they developed a process to simulate solar radiation using an Adaptive Neuro-Fuzzy Inference System (ANFIS). The ANFIS network has three neurons in the input layer, and one neuron in the output layer. The inputs were monthly mean maximum temperature (Tmax), monthly mean minimum temperature (Tmin), and monthly mean sunshine duration (n). The performance of the system was obtained through the simulation results. The ANFIS results were compared with experimental results using root-mean-square error (RMSE) and coefficient of determination $\left(\mathrm{R}^{2}\right)$. The results signify an improvement in predictive accuracy and ANFIS capability to estimate solar radiation. The statistical characteristics of $\mathrm{RMSE}=1.0854$ and $\mathrm{R}^{2}=0.8544$ were obtained in the training phase and RMSE $=1.7585$ and $\mathrm{R}^{2}=0.6567$ in the testing phase. As a result, the model was deemed an efficient technique to predict global solar radiation for practical purposes.

Prediction of global solar radiation using Artificial Neural Network was carried out by [7] in Warrri, Nigeria. The study employed this method since installation of pyranometer was a very expensive and uncommon exercise. The results obtained show that the maximum values of global solar radiation occurs in April and December with $15.94 \mathrm{MJm}^{-2} \mathrm{day}^{-1}$, and $15.98 \mathrm{MJm}^{-2}$ day $^{-1}$ respectively during dry season while minimum values of $11.02 \mathrm{MJm}^{-2} \mathrm{day}^{-1}, 11.30 \mathrm{MJm}^{-2} \mathrm{day}^{-1}, 12.31 \mathrm{MJm}-2$ day-1, $12.91 \mathrm{MJm}^{-2}$ day $^{-1}$, was observed in February, May, June, July, and August, respectively during rainy season. From the close relationship that exist between measured and Artificial Neural Network predicted results, it is obvious that Artificial Neural Network model is a better model for solar radiation prediction.

A study of 27 years of girded daily rainfall data was done by [8]. The data used was obtained from a combined dataset by the National Centre for Environmental Prediction and Climate Research Unit reanalysis data (NCEP-CRU) for spatial-temporal variability of monthly amounts and frequency in rainfall and rainfall trends. Temporal variability was assessed using the percentage coefficient of variation while temporal trends in rainfall were assessed using maps of linear regression slopes for the months of May through October. These 6 months comprise of the period of the onset and end of the rainy season throughout the region. Monthly rainfall amount and frequency were then predicted over a 24-month period using the Auto Regressive Integrated Moving Average (ARIMA) Model. The predictions were evaluated using NCEP-CRU data for the same period. Kolmogorov Smirnov test results suggest that despite there are some months during the rainy season (MayOctober) when there is no significant agreement $(\mathrm{p}<0.05)$ between the monthly distribution of the values of the model and the corresponding 24-month NCEP-CRU data, the model performed better than simply replicating the long term mean of the data used for the prediction. Overall, the model does well in areas and months with lower temporal rainfall variability.

To predict consumer indices in the Republic of Yemen to the price of the period between 1/1/2005 and 1/1/2014, [9] applied two forecasting methods, Box-Jenkins statistical model and a modified artificial neural network model (in which adaptive slope and momentum parameter are used to update the weights in back propagation neural network). Their analysis was based on the following statistical standards: Mean Square Error (MSE), Mean Absolute Error (MAE), Root Mean Square Error (RMSE), and Mean Absolute Percentage Error (MAPE). The comparison between the two forecasting models showed that the modified artificial neural network model gave lower errors and higher accuracy for the prediction of time series data during training and testing.

The use of data mining techniques in forecasting maximum temperature, rainfall, evaporation and wind speed was examined. It was performed using Artificial Neural Network and Decision Tree algorithms for meteorological data collected between 2000 and 2009 from the city of Ibadan, Nigeria [10]. During their 
analysis a data model for the meteorological data was developed and this was used to train the classifier algorithms. The performances of these algorithms were compared using standard performance metrics (Correlation Coefficient, Mean Squared Error and the Mean-squared Error), and the algorithm which gave the best results used to generate classification rules for the mean weather variables. A predictive Neural Network model was also developed for the weather prediction program and the results compared with actual weather data for the predicted periods. The results show that given enough case data, Data Mining techniques can be used for weather forecasting and climate change studies.

In [11], simple mathematical models based on trigonometric functions for the daily maximum and minimum dry-bulb temperatures, and hourly dry-bulb temperature to simulate the long-term measured data was derived. The coefficients of the recommended models for 78 provinces of Turkey were determined using the hourly data measured during at least 15years. It was seen that the statistical indicators for the models such as mean absolute error, root mean square error and correlation coefficient are at acceptable levels. The models can also be used to describe temperatures for other locations in Turkey.

A two statistical single-station short-term forecast schemes was introduced in [12] and was applied to realtime weather prediction. A multiple regression model predicting the temperature anomaly and multiple regression Markov model forecasting the probability of precipitation were shown. The study conducted the following forecast experiments in central European weather stations: The single-station performance of the statistical models; a linear error minimizing combination of independent forecasts of numerical weather prediction and statistical models, and the forecast representation for a region deduced by applying a suitable interpolation technique. This leads to an operational weather forecasting system for the temperature anomaly and the probability of precipitation; the statistical techniques demonstrated provide a potential for future applications in operational weather forecasts.

A new discrete grey least squares support vector machine as a method for time series prediction was proposed by [13]. His algorithm combines the advantages of Discrete Grey Model (DGM $(1,1)$ ) and Least Squares Support Vector Machine (LS-SVM) such as needs for little origin data, simple calculate process, higher forecasting accuracy, simplicity in problem formulation and implementation. The validity and practicality of this model is verified through an example's program simulation using the MAE, MARPE and MSRE indices. The result showed that though the proposed model overcame the defects of parameters estimate in traditional DGM $(1,1)$ model, they may be superior to other modelling methods in some aspects. The method has some potential drawbacks such as the selection of trade-off parameter related to a least squares cost function. The performance of the model is more related to the selection of trade-off parameter.

The literatures reviewed above highlighted the most widely used techniques for prediction as Regression analysis, clustering and Artificial Neural Network (ANN). This present study compared several techniques in other to get the best method for weather prediction.

\section{Materials and Methods}

The current study was carried out in the south eastern Nigeria specifically, Enugu, Abakaliki and Owerri. Daily mean temperature data records for a period of 10years (2005-2015) and daily minimum and maximum temperature data records for a period of over two months (22Jan - 10Apr) of the study locations was obtained from Nigerian Meteorological Agency (NIMET), Enugu. The study applied the data acquired to several forecasting models: $3 \& 4$ point moving averages (MA), the Single Exponential Smoothing (SES) and the time dependent regression model for intercept and non-intercept models as well as linear and non-linear models.

The aim of regression approach is to determine the best regression approach in fitting temperature data and compare them with the other methods. A simple regression model may either be intercept or non-intercept. The intercept model is one that does not pass through the origin while the non-intercept is one that passes through the origin. Depending on the nature of data either of them can give a good model.

A simple regression can also be linear or nonlinear depending on the nature and distribution of the data 
involved. This study compared several regression models based on such characteristics, together with already mentioned techniques. The regression analysis compared the linear, logarithmic, inverse, quadratic, compound, growth, cubic, exponential, power and logistic models for both intercept and non-intercept models. The model comparisons were made based on the following performance evaluation methods: Mean Square Error (MSE), Root Mean Square Error (RMSE) and the F-value where applicable.

\section{Results and Discussion of Findings}

A comparison of the models (Moving Averages, Logarithmic, Power and Single Exponential Smoothing (SES) show that the power model consistently gave the best result with highest F-value: 1513.71(Enugu), 1523.622(Abakaliki), 1514.103(Owerri), and least MSE and RMSE results: 0.655(Enugu), 0.6495(Abakaliki), 0.5925(Owerri), and 0.80524(Enugu), 0.80292(Abakaliki), 0.76703(Owerri) respectively. This is followed by the single exponential smoothing technique and then the logarithmic model. The intercept model did not give any significant result in this study while the moving average fared badly as a forecasting model for temperature. Also observations from trends of actual and power model predicted minimum and maximum temperature graphs (figs 1-6) show that a good number of power model predicted values coincided with the actual values with slight difference observed in maximum temperatures of actual and predicted in Abakaliki. The trends of the actual and predicted temperatures proved that the power model fits the data better than other models.

The summary result for the three best forecasting models of temperature is presented in Table 1 below:

Table 1. Summary Result of the Best Three Forecasting Models

\begin{tabular}{|c|c|c|c|c|c|c|c|}
\hline Location & Model & $\mathrm{R}$ & $\mathrm{F}$ & MSE & RMSE & B & P-VALUE \\
\hline \multirow[t]{3}{*}{ Enugu } & $\begin{array}{l}\text { LOG } \\
\end{array}$ & 96.675 & 1410.21 & 2253.988 & 28.12139 & 6.954 & 0 \\
\hline & POWER & 96.875 & 1513.71 & 0.655 & 0.805244 & 0.8355 & 0 \\
\hline & SES & & & 2.1825 & 1.476021 & & \\
\hline \multirow[t]{3}{*}{ Abakaliki } & LOG & 96.7 & 1440.839 & 48.60075 & 6.738416 & 6.848 & 0 \\
\hline & POWER & 97.375 & 1523.622 & 0.6495 & 0.802923 & 0.83525 & 0 \\
\hline & SES & & & 2.18 & 1.475193 & & \\
\hline \multirow[t]{3}{*}{ Owerri } & LOG & 74.2 & 1429.403 & 47.44 & 6.694751 & 6.7665 & 0 \\
\hline & POWER & 96.875 & 1514.103 & 0.5925 & 0.76703 & 0.79525 & 0 \\
\hline & SES & & & 2.415 & 1.541488 & & \\
\hline
\end{tabular}

\subsection{Power Regression Model}

For this study, equation of power regression model is given as;

$\mathrm{T}_{(\max / \mathrm{min})}=\mathrm{f}\left(\mathrm{T}_{\mathrm{d}}\right)$

The maximum temperature is modelled as;

$\Rightarrow \ln \operatorname{Tmax}=\beta_{1} \ln \left(\mathrm{T}_{\mathrm{d}}\right)$

Where: $\mathrm{T}_{\max }$ is maximum temperature value, and $T_{d}$ is the time (in day) in which the maximum temperature was read.

$\beta_{1}$ is the regression coefficient, i.e. the rate of change of maximum temperature with respect to time.

The predicted maximum temperature is then given as; 
$\widehat{T}_{\max }=\left(T_{d-1}\right)^{\beta_{1}}$

Where: $\widehat{T}_{\max }$ is predicted maximum temperature value for a given time, $T_{d}$.

$T_{d-1}$ is the time before the time of predicted maximum temperature.

$\beta_{1}$ is as defined above.

Similarly,

The minimum temperature is modelled as

$\Rightarrow \operatorname{lnTmin}=\beta_{2} \ln \left(T_{d}\right)$

Where: $T_{\min }$ is minimum temperature value, and $T_{d}$ is the time (in day) in which the minimum temperature was read.

$\beta_{2}$ is the regression coefficient, i.e. the rate of change of minimum temperature with respect to time.

The predicted minimum temperature is then given as;

$\widehat{T}_{\min }=\left(T_{d-1}\right)^{\beta_{2}}$

Where: $\widehat{T}_{\min }$ is predicted minimum temperature value for a given time, $T_{d}$.

$T_{d-1}$ is the time before the time of predicted minimum temperature.

$\beta_{2}$ is as defined above.

The model is implemented in Excel for temperature forecasting as given below:

$T_{(\min / \max )}=\operatorname{EXP}(\operatorname{TREND}(\operatorname{LN}(B 11: B 20), L N(A 11: A 20), L N(A 21)))$

Where: B11:B20 is the range of ten maximum or minimum temperature values recorded in previous days the predicted maximum or minimum temperature value is computed.

A11:A20 is the range of ten previous days the predicted maximum/minimum temperature value is computed.

A21: is the day the predicted maximum/minimum temperature value is computed.

For day $1=$ January 1 and day 365= December 31

EXP, TREND and LN are Excel functions.

The given Excel formula was used to predict daily minimum and maximum temperature values for more than 2 months period.

\subsection{Comparison of Actual and Predicted Minimum and Maximum Temperature Values for the Three Best}

Models in the Corresponding Periods

\section{A. Comparison of Actual and Predicted Minimum and Maximum Values for the Power Model}

Figs 1-6 show graphs comparison of actual and power model predicted minimum and maximum temperatures against day for more than two months period. Observations from the graphs show that a good number of predicted values coincided with the actual values with slight difference observed in maximum temperatures of actual and predicted in Abakaliki. The trends of the actual and predicted temperatures prove that the power model gives the most efficient predictions for the three cities. 


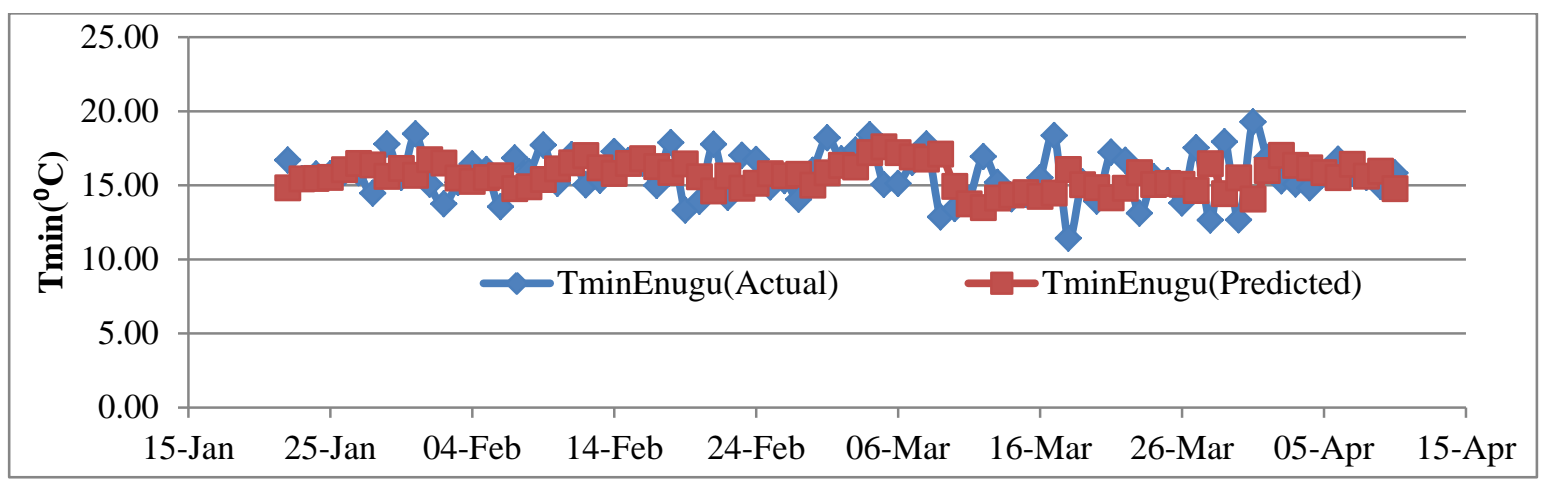

Fig.1. Trend of Actual and Predicted Daily Minimum Temperature Values for Enugu for Period of over 2months

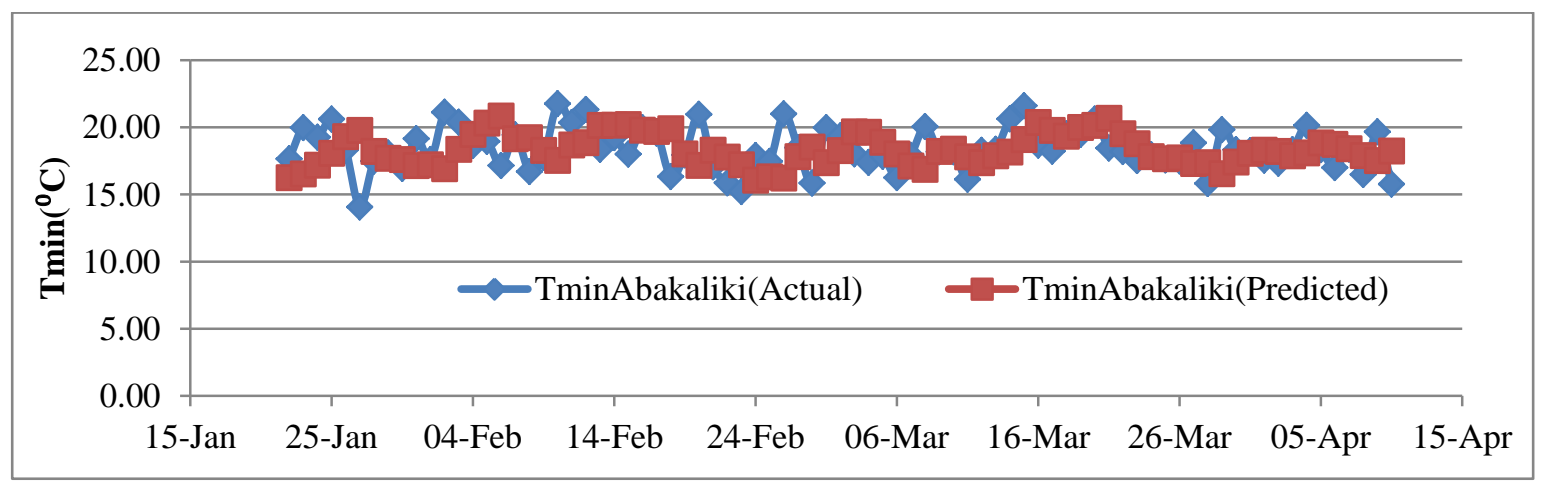

Fig.2. Trend of Actual and Predicted Daily Minimum Temperature Values for Abakaliki for Period of over 2months.

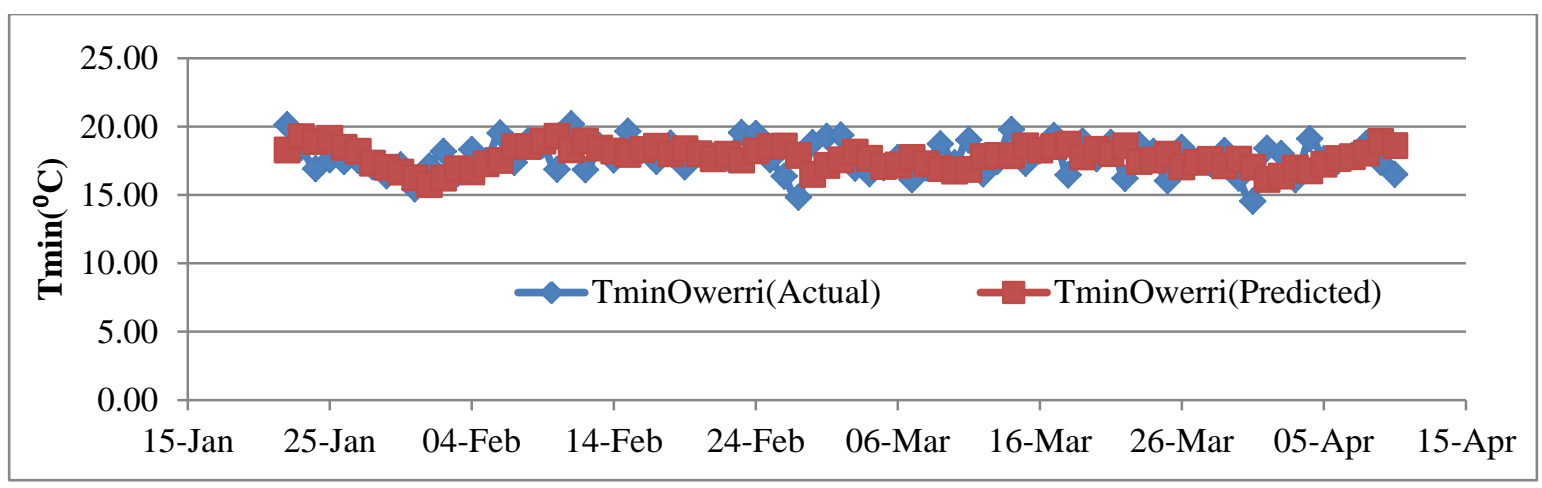

Fig.3. Trend of Actual and Predicted Daily Minimum Temperature Values for Owerri for Period of over 2months. 


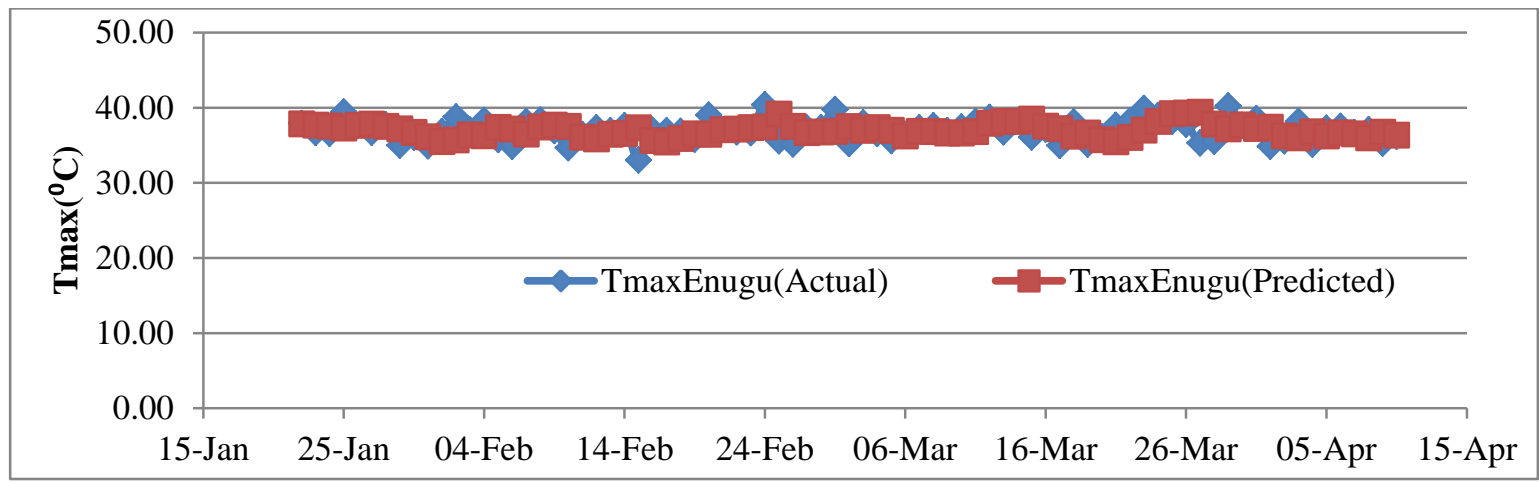

Fig.4. Trend of Actual and Predicted Daily Maximum Temperature Values for Enugu for Period of over 2months.

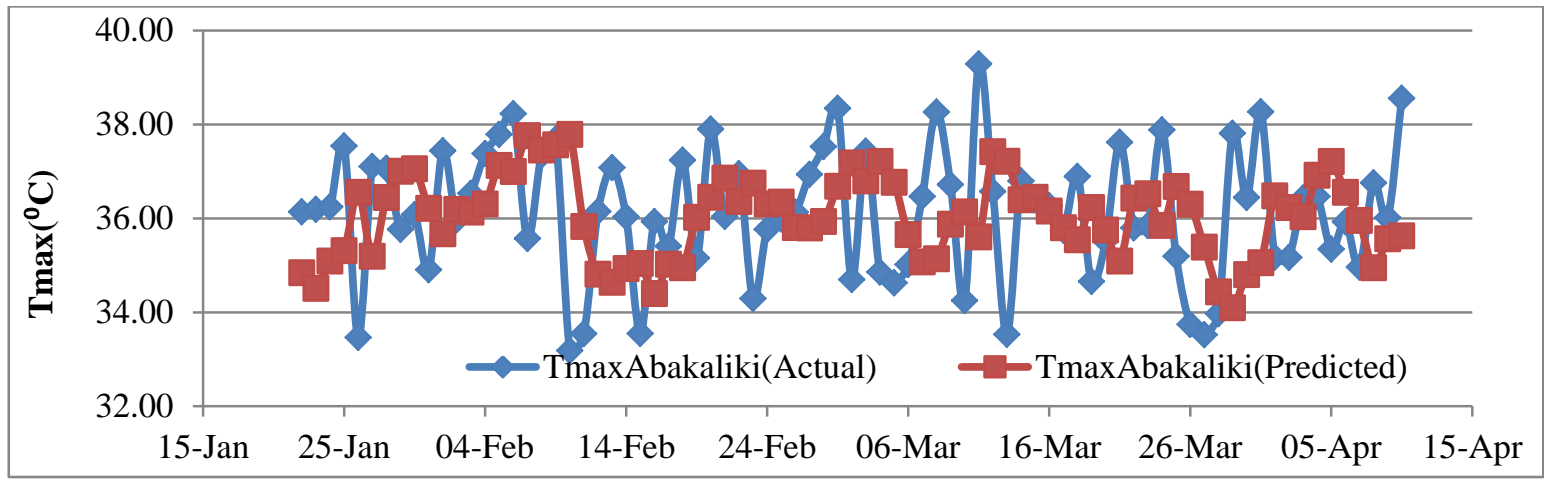

Fig.5. Trend of Actual and Predicted Daily Maximum Temperature Values for Abakaliki for Period of over 2months.

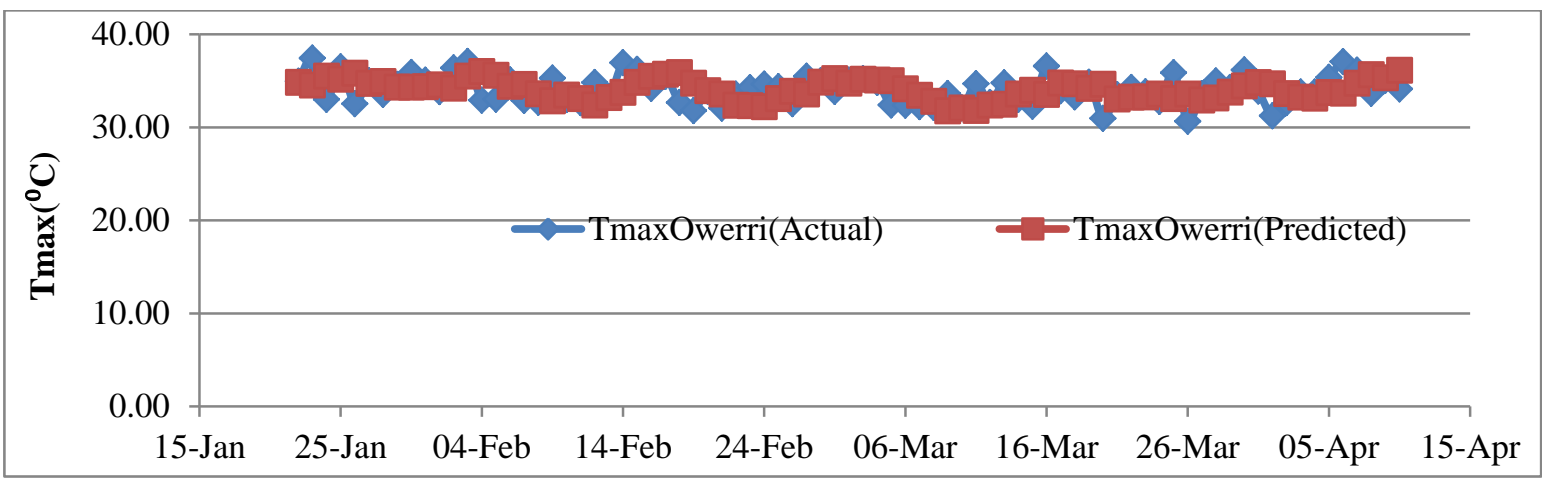

Fig.6. Trend of Actual and Predicted Daily Maximum Temperature Values for Owerri for Period of over 2months.

\section{B. Comparison of Actual And Predicted Minimum and Maximum Values for the SES Model}

Figs 7-12 show graphs comparison of actual and SES model predicted minimum and maximum temperatures against day for more than two months period. The graphs show that very few predicted temperature values follow the trends of actual temperatures while the rest do not coincide. This shows that SES prediction model is ineffective for temperature prediction in the three cities when compared with the power model. 


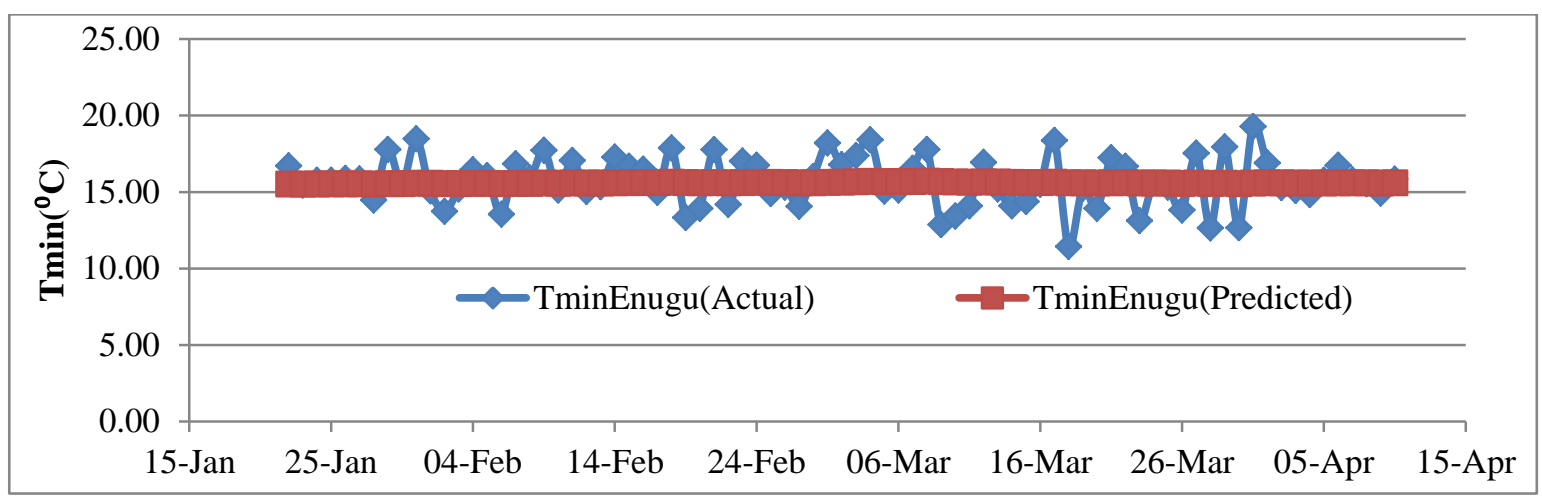

Fig.7. Trend of Actual and Predicted Daily Minimum Temperature Values for Enugu for Period of over 2months.

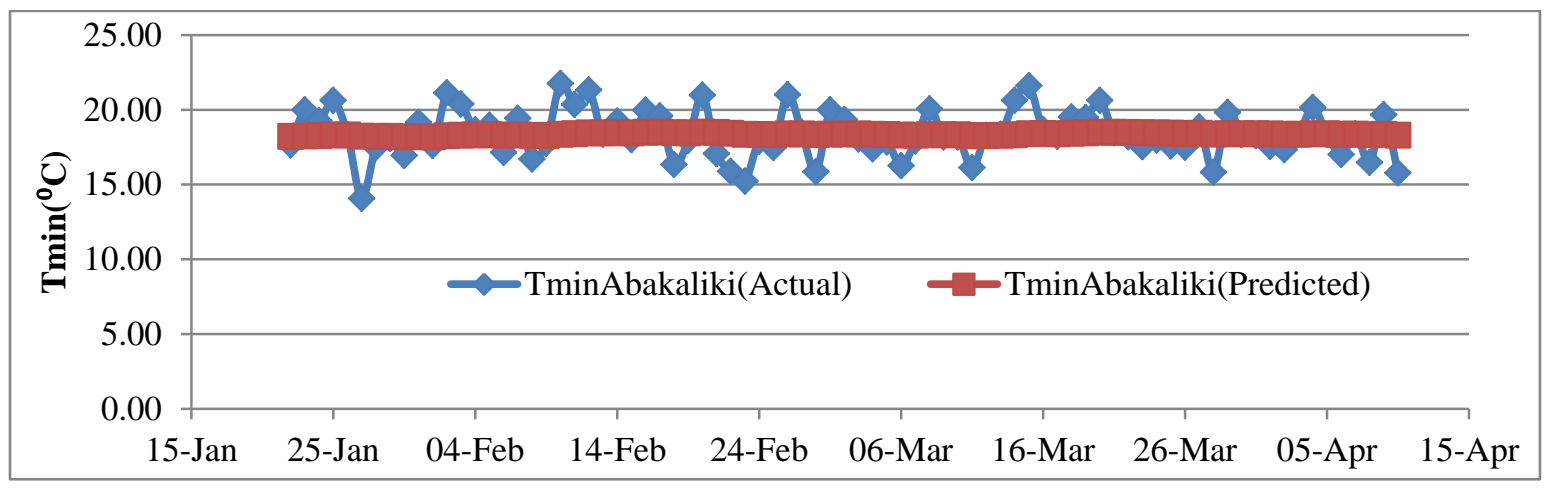

Fig.8. Trend of Actual and Predicted Daily Minimum Temperature Values for Abakaliki for Period of over 2months.

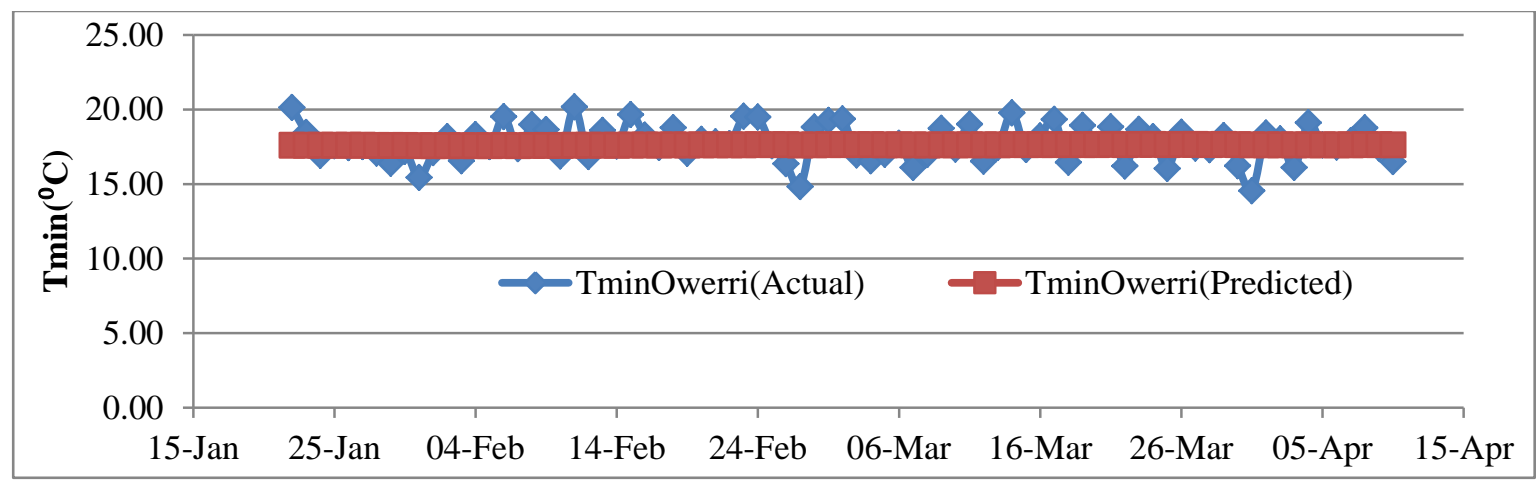

Fig.9. Trend of Actual and Predicted Daily Minimum Temperature Values for Owerri for Period of over 2months. 


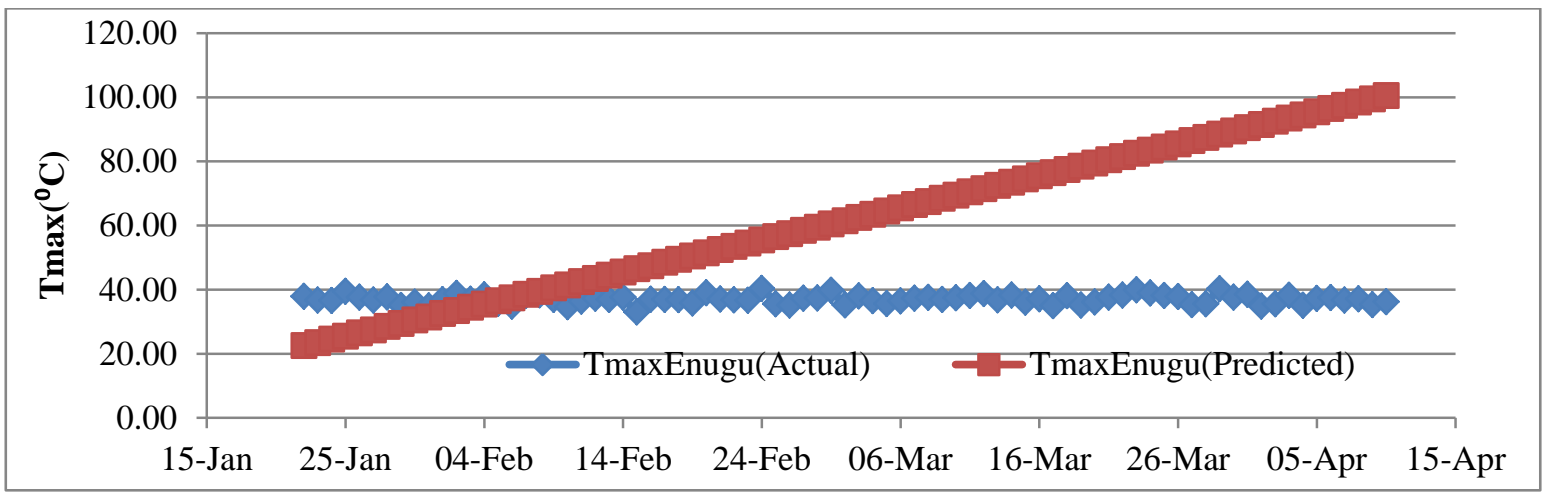

Fig.10. Trend of Actual and Predicted Daily Maximum Temperature Values for Enugu for Period of over 2months.

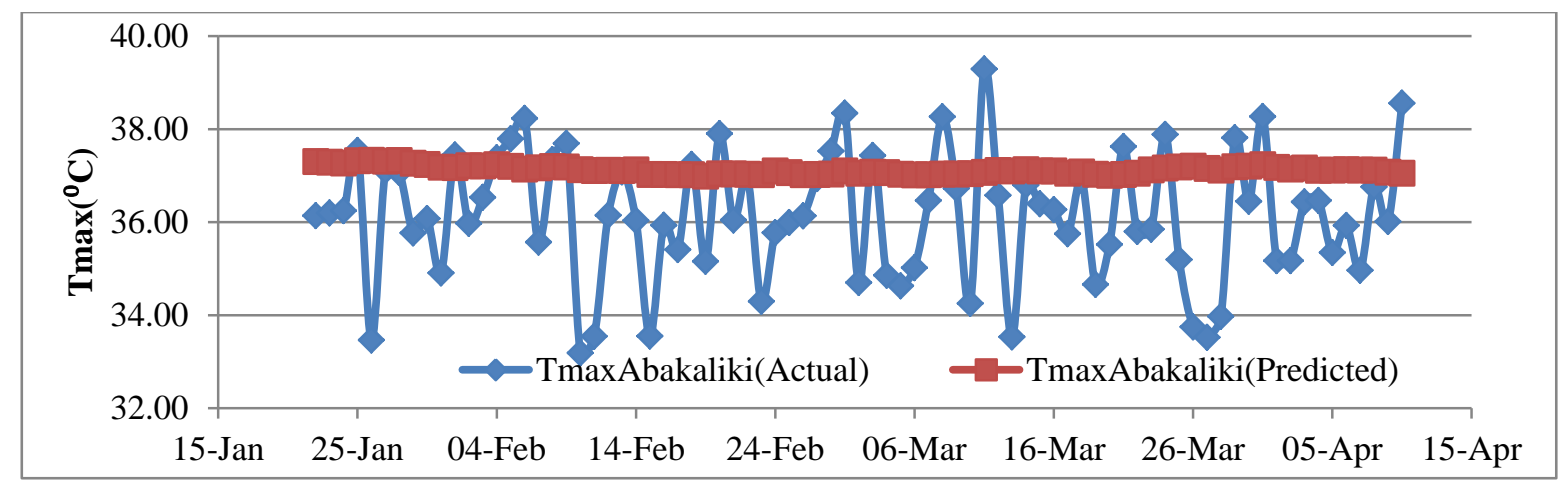

Fig.11. Trend of Actual and Predicted Daily Maximum Temperature Values for Abakaliki for Period of over 2months.

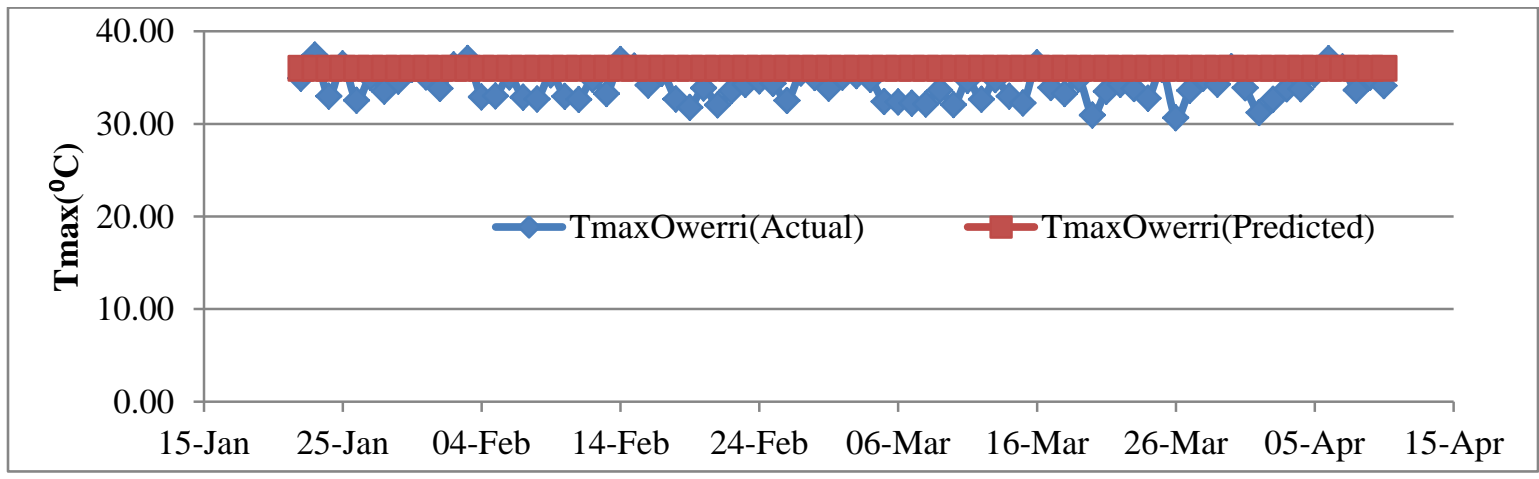

Fig.12. Trend of Actual and Predicted Daily Maximum Temperature Values for Owerri for Period of over 2months.

\section{Comparison of Actual \& Predicted Minimum and Maximum Values for the Logarithmic Model}

Figs 13-18 show graphs comparison of actual and logarithmic model predicted minimum and maximum temperatures against day for more than two months period. Observations show that with the exception of few values, most of the predicted temperature values don't agree with actual temperatures. Therefore, the power model is a better model for predicting temperature values of the three cities. 


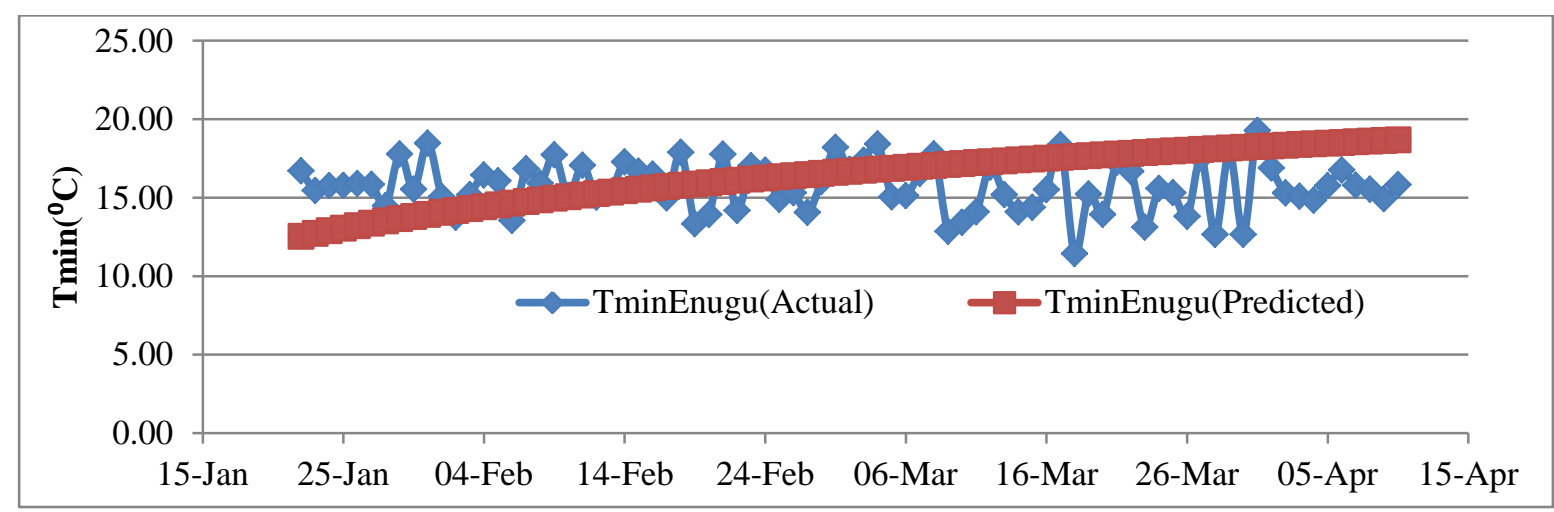

Fig.13. Trend of Actual and Predicted Daily Minimum Temperature Values for Enugu for Period of over 2months.

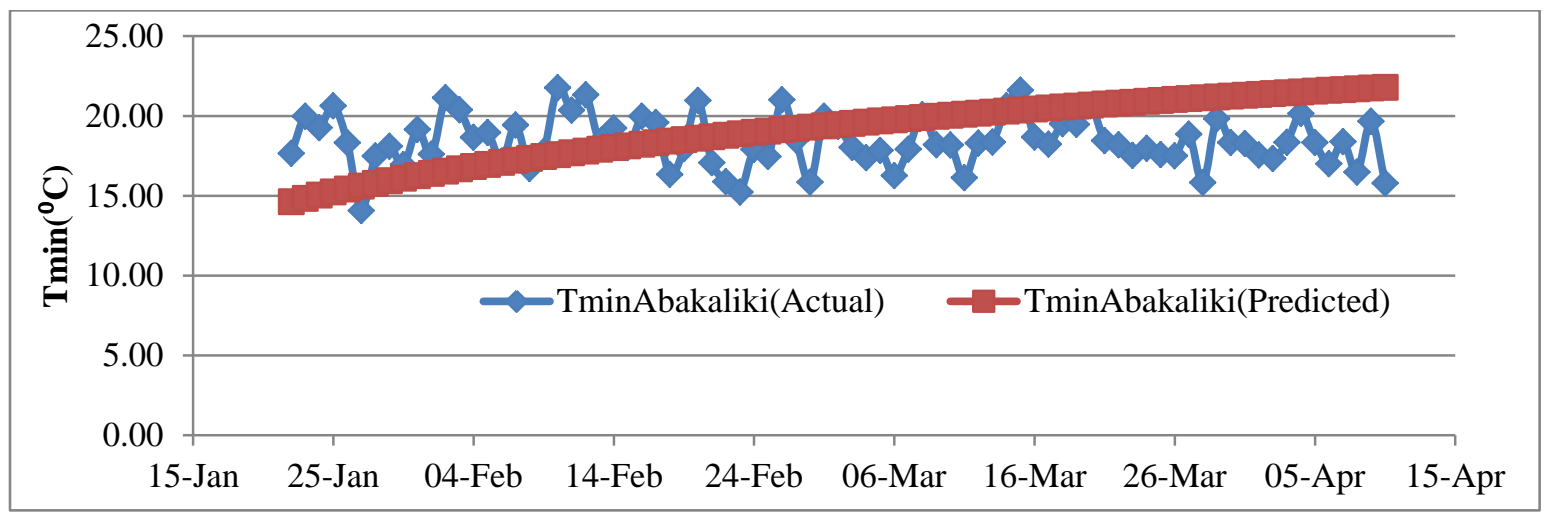

Fig.14. Trend of Actual and Predicted Daily Minimum Temperature Values for Abakaliki for Period of over 2months.

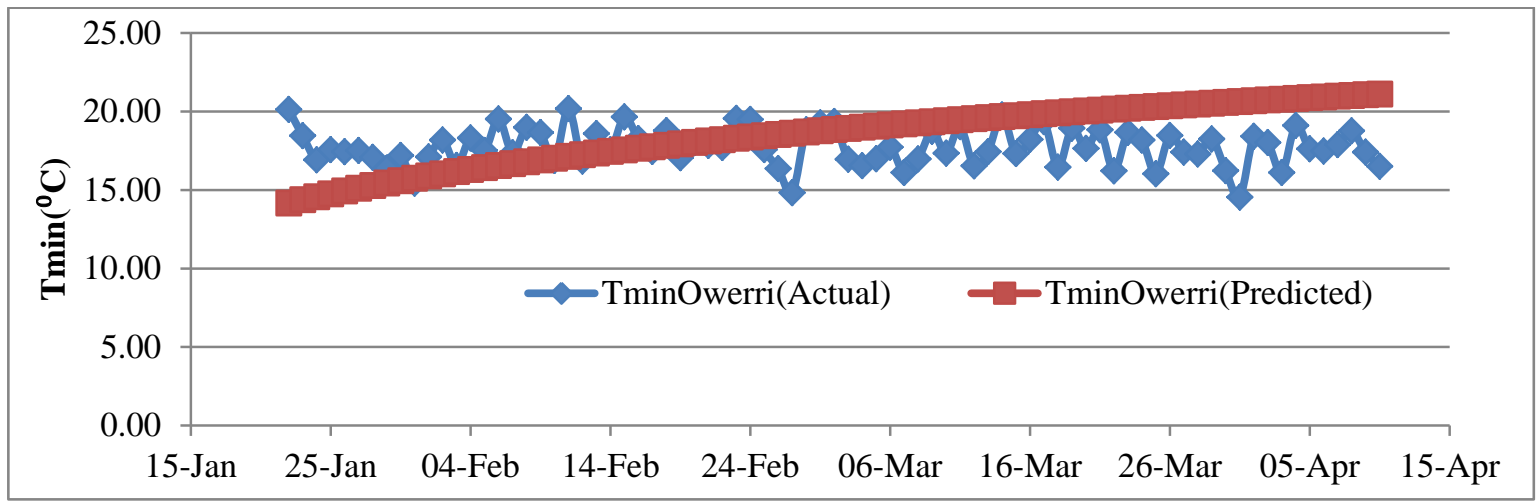

Fig.15. Trend of Actual and Predicted Daily Minimum Temperature Values for Owerri for Period of over 2months. 


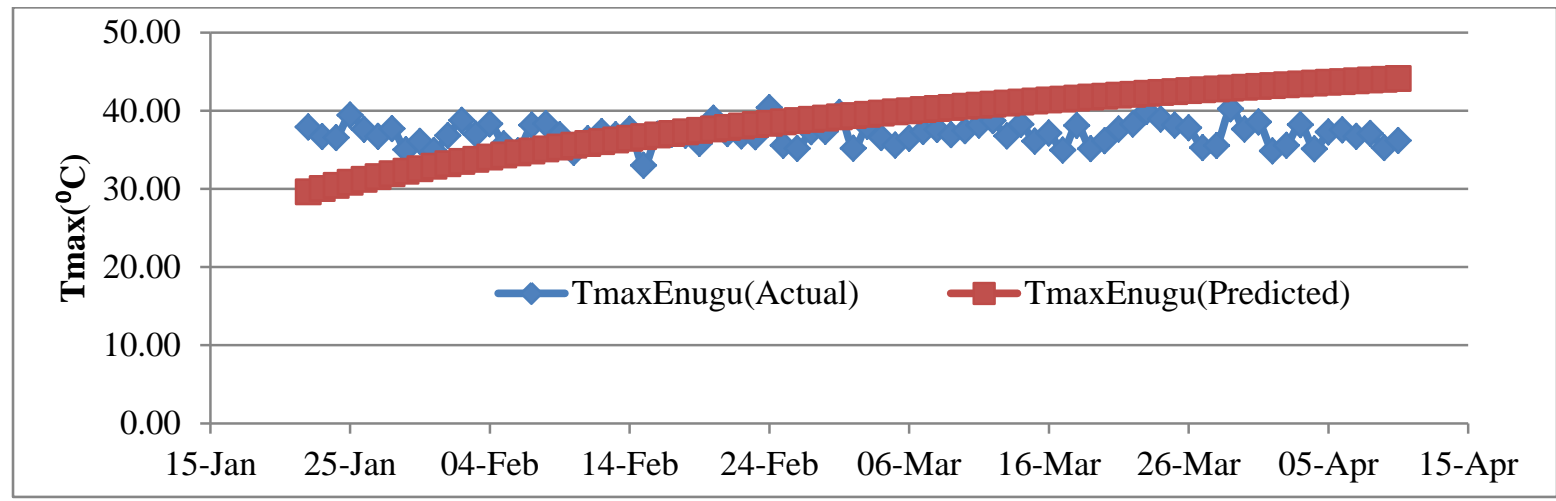

Fig.16. Trend of Actual and Predicted Daily Maximum Temperature Values for Enugu for Period of over 2months.

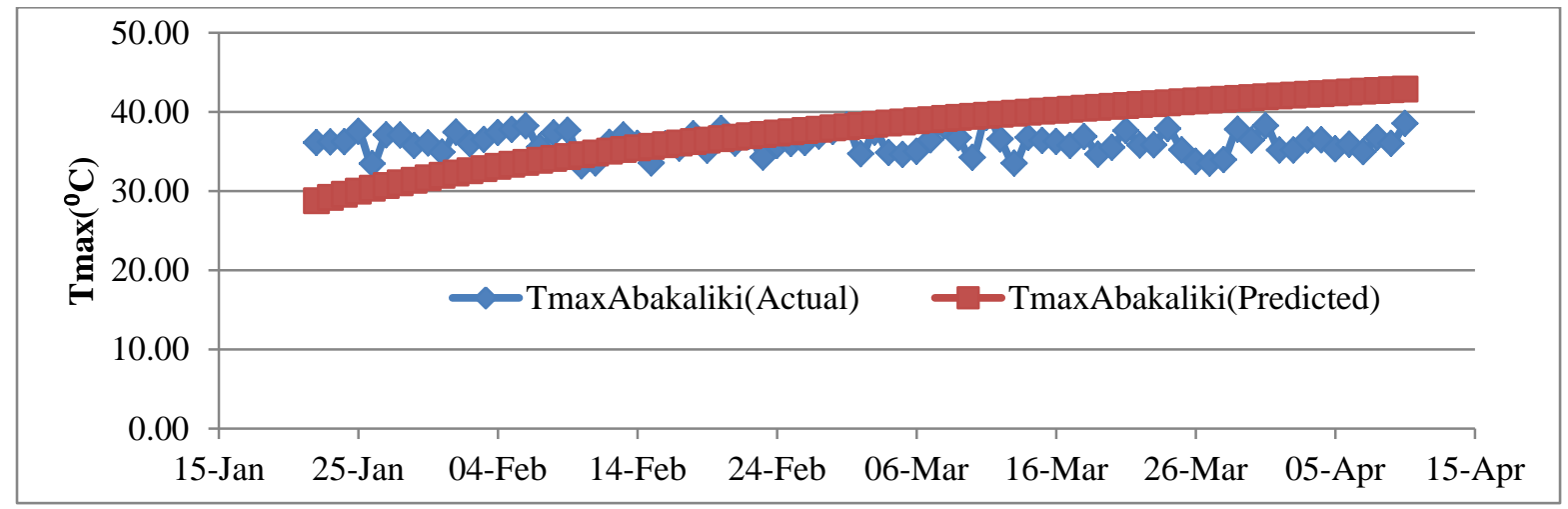

Fig.17. Trend of Actual and Predicted Daily Maximum Temperature Values for Abakaliki for Period of over 2months.

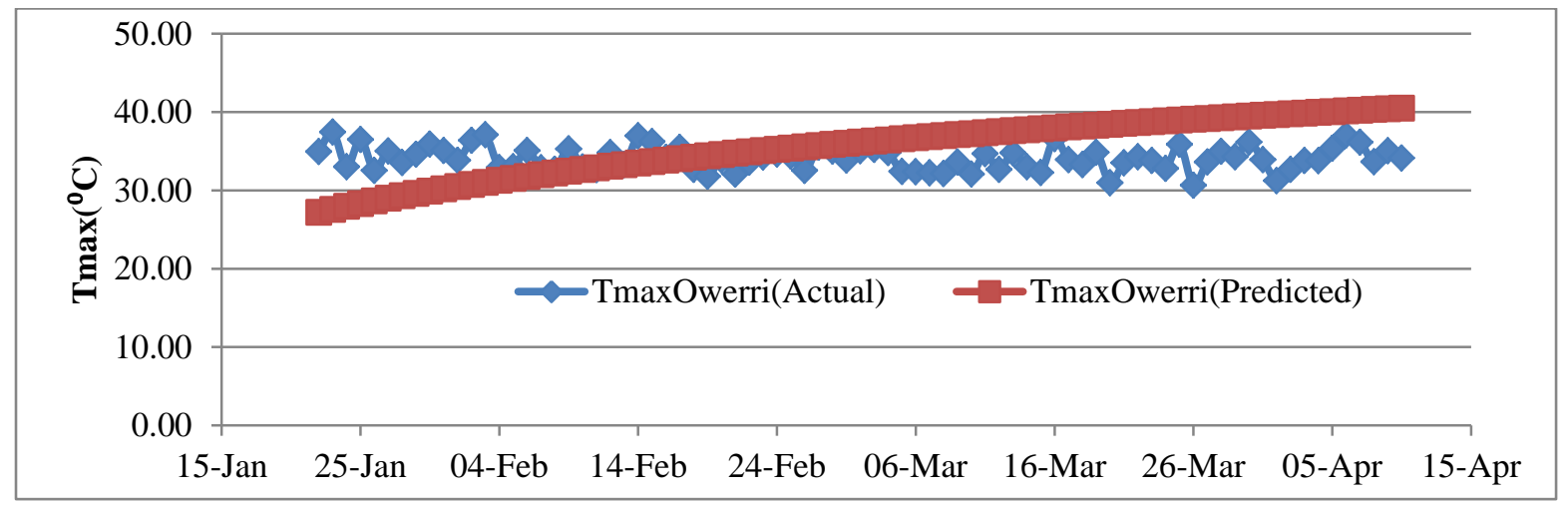

Fig.18. Trend of Actual and Predicted Daily Maximum Temperature Values for Owerri for Period of over 2months.

\section{Conclusion}

The aim of this study was to find an efficient and robust model for building temperature information systems in South-East Nigeria. The comparison of various forecasting models shows that the power model is the best 
model for temperature information systems because of its minimum errors as shown by its statistical characteristics and graph trends. This is followed by the single exponential smoothing technique and logarithmic model. This study therefore recommends the power model for temperature prediction in the SouthEast of Nigeria and more specifically, Enugu, Abakaliki and Owerri.

\section{References}

[1] J. A. Nwanta, S. V. O. Shoyinka, K. F. Chah et al., "Production characteristics, disease prevalence, and herd-health management of pigs in Southeast Nigeria "J Swine Health Prod., vol. 19, no. 6, pp. 331-339, 2011.

[2] J. C. Okafor and E.C.M. Fernandes, "Compound farms of south-eastern Nigeria: A predominant agroforestry homegarden system with crops and small livestock" Agroforestry Systems vol. 5, issue 2, pp. 153-168, 1987. https://doi.org/10.1007/BF00047519

[3] A. H. Igweze, M. N. Amagoh and A. N. Ashinze, "Analysis of rainfall variations in the Niger Delta region of Nigeria", Journal of Environmental Science, Toxicology and Food Technology, vol. 8, issue 1, ver. vi, pp. 25-30, 2014.

[4] E. C. Onyenechere, "Climate change and spatial planning concerns in Nigeria: Remedial measures for more effective response", Journal of Human Ecology, vol. 32, no. 3, pp. 137-148, 2010.

[5] A. Ogbo, E. L. Ndubuisi and W. Ukpere, "Risk management and challenges of climate change in Nigeria", Journal of Human Ecology, vol. 41, no. 3, pp. 221-235, 2013.

[6] L. Olatomiwa, S. Mekhilef, S. Shamshirband, et al., "Adaptive neuro-fuzzy approach for solar radiation prediction in Nigeria", Renewable and Sustainable Energy Reviews, vol. 51, pp.1784-1791, 2015. https://doi.org/10.1016/j.rser.2015.05.068

[7] G. F. Ibeh, G. A. Agbo, P. E. Agbo et al., "Application of Artificial Neural Networks for Global Solar Radiation Forecasting With Temperature", Advances in Applied Science Research, vol. 3, no. 1, pp. 130134, 2012.

[8] U. M. Bibi, J. Kaduk and H. Balzter, "Spatial-Temporal Variation and Prediction of Rainfall in Northeastern Nigeria", Climate, vol.2, no.3, pp.206-222, 2014. https://doi.org/10.3390/cli2030206

[9] B. M. Al-Maqaleh, A. A. Al-mansoub and F. N. Al-Badani, "Forecasting using Artificial Neural Network and Statistics Models" International Journal of Education and Management Engineering, vol. 3, pp. 20-32, 2016. https://doi.org/10.5815/ijeme.2016.03.03

[10] F. Olaiya and A. B. Adeyemo, "Application of Data Mining Techniques in Weather Prediction and Climate Change Studies" International Journal of Information Engineering and Electronic Business, vol. 1, pp.51-59, 2012. https://doi.org/10.5815/ijieeb.2012.01.07

[11] H. Bulut, O. Buyukalaca and T. Yilmaz, "New models for simulating daily minimum, daily maximum and hourly outdoor temperatures", In Proceedings of the first international exergy, energy and environment symposium (IEEES-1), Izmir, Turkey, pp. 499-504, 2003.

[12] C. C. Raible, G. Bischof, K. Fraedrich et al., "Statistical single-station short-term forecasting of temperature and probability of precipitation: Area interpolation and NWP combination", Weather and Forecasting, vol. 14, no. 2, pp. 203-214, 1999.https://doi.org/10.1175/15200434(1999)014<0203:SSSSTF>2.0.CO;2

[13] D. Zhou, "Time Series Forecasting Model Based on Discrete Grey LS-SVM" International Journal of Intelligent Systems and Applications, vol. 02, pp. 27-33, 2015. https://doi.org /10.5815/ijisa.2015.02.04 


\section{Authors' Profiles}

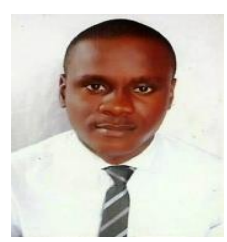

Anthony T. Umerah is currently pursuing his M.Sc. at Ebonyi State University Abakaliki, Ebonyi State, Nigeria. He received his BSc in computer science from Nnamdi Azikiwe University Awka, Anambra State, Nigeria in 2010. His research interests include Modelling and Simulation of Computing Systems. This publication is part of his ongoing dissertation work to be soon completed. He is currently not affiliated to any institution, whether research or academics.

Eric C. Okafor is currently a Professor in the Department of Computer Engineering, Enugu State University of Science and Technology, Enugu State, Nigeria. He received his PhD in Digital Systems and Computer Engineering from University of Nigeria, Nsukka Nigeria. His research interest is in the area of Intelligent Systems Engineering.

How to cite this paper: Anthony T. Umerah, Eric C. Okafor,"A Model for Implementing Temperature Information Systems in South-east Nigeria", International Journal of Education and Management Engineering(IJEME), Vol.8, No.5, pp.51-64, 2018.DOI: 10.5815/ijeme.2018.05.06 